Research Article

\title{
Association between molecular markers and behavioral phenotypes in the immatures of a butterfly
}

\author{
Janaína De Nardin ${ }^{1}$, Vanessa Buffon ${ }^{2}$, Luís Fernando Revers $^{2}$ and Aldo Mellender de Araújo ${ }^{1}$ \\ ${ }^{1}$ Programa de Pós-Graduação em Genética e Biologia, Departamento de Genética, Universidade Federal \\ do Rio Grande do Sul, Porto Alegre, RS, Brazil. \\ ${ }^{2}$ Laboratório de Genética Molecular Vegetal, Centro Nacional de Pesquisa de Uva e Vinho, Empresa \\ Brasileira de Pesquisa Agropecuária (EMBRAPA) Uva e Vinho, Bento Gonçalves, RS, Brazil.
}

\begin{abstract}
Newly hatched caterpillars of the butterfly Heliconius erato phyllis routinely cannibalize eggs. In a manifestation of kin recognition they cannibalize sibling eggs less frequently than unrelated eggs. Previous work has estimated the heritability of kin recognition in $H$. erato phyllis to lie between 14 and $48 \%$. It has furthermore been shown that the inheritance of kin recognition is compatible with a quantitative model with a threshold. Here we present the results of a preliminary study, in which we tested for associations between behavioral kin recognition phenotypes and AFLP and SSR markers. We implemented two experimental approaches: (1) a cannibalism test using sibling eggs only, which allowed for only two behavioral outcomes (cannibal and non-cannibal), and (2) a cannibalism test using two sibling eggs and one unrelated egg, which allowed four outcomes [cannibal who does not recognize siblings, cannibal who recognizes siblings, "super-cannibal" (cannibal of both eggs), and "super non-cannibal" (does not cannibalize eggs at all)]. Single-marker analyses were performed using $\chi^{2}$ tests and logistic regression with null markers as covariates. Results of the $\chi^{2}$ tests identified 72 associations for experimental design 1 and 73 associations for design 2 . Logistic regression analysis of the markers found to be significant in the $\chi^{2}$ test resulted in 20 associations for design 1 and 11 associations for design 2. Experiment 2 identified markers that were more frequently present or absent in cannibals who recognize siblings and super non-cannibals; i.e. in both phenotypes capable of kin recognition.
\end{abstract}

Keywords: Kin discrimination, caterpillar-egg cannibalism, Lepidoptera, Heliconius, AFLP.

Received: March 15, 2017; Accepted: August 1, 2017.

\section{Introduction}

The evolution of morphological, behavioral and life history traits is underpinned by the evolution of a large number of loci (Lynch and Walsh, 1998; Erickson et al., 2004). Quantitative traits are under polygenic control. As a consequence, they frequently show continuous variation within and between populations (Falconer and Mackay, 1996); however, as in the case of threshold traits, their phenotypic variation does not need to be linear (Roff et al., 1999). Evolutionary biologists have sought to examine the genetic basis of these traits. One approach relies on the use of molecular markers to identify quantitative trait loci (QTLs), i.e. genetic loci that contribute to quantitative traits (Lynch and Walsh, 1998; Erickson et al., 2004).

Genetic mapping of QTLs has become a routine tool to study plants, animals and humans. The available methods fall into two main categories that are based on related

Send correspondence to Janaína De Nardin, Departamento de Genética, Universidade Federal do Rio Grande do Sul. Av. Bento Gonçalves, 9500, Prédio 43323, 91501-970 Porto Alegre, RS, Brazil. E-mail: janaina.dn@gmail.com. genetic principles: linkage analysis and association studies (Olson et al., 1999; Wu et al., 2002). Here we use a study design that relies on association analysis. Genetic association studies are designed to identify genetic loci where allelic states are correlated with the phenotype of interest. The associations of interest are causal and identify loci whose different alleles have different effects on the phenotype. However, even if the causal locus itself is not genotyped it may be possible to identify it indirectly through association with genotyped loci that are located nearby in the genome (Astle and Balding, 2009). A recent advance is genome-wide association analysis, in which a large number of single locus tests are performed to examine marker loci covering the entire genome for association with the phenotype (Bush and Moore, 2012). Each single-marker test assesses the segregation of a phenotype with respect to the marker genotype, indicating which markers are associated with the phenotypic trait of interest and pointing to the existence of potential QTLs in the genomic neighborhood of associated markers (Doerge, 2002). 
Lepidoptera is a diverse clade that has long attracted the attention of biologists interested in ecological and evolutionary processes, from the classical studies of Edmund Ford (Ford, 1964, 1975) on Maniola jurtina and other butterflies and moths, to Kettlewell's experiments (Kettlewell, 1955 ) on selection in industrial melanism, until recent studies on butterflies of the genus Heliconius (Merrill et al., 2015).

Heliconius butterflies are a well-established model for studies of ecology, natural selection and speciation (Brown Jr, 1981; Jiggins et al., 2005; Joron et al., 2011). As the most widespread species of the genus, Heliconius erato is present in many habitats and forest types, from Mexico to northern Argentina. Of all subspecies, $H$. erato phyllis has the widest geographical distribution, as well as greatest environmental tolerance (Ramos and Freitas, 1999).

The newly hatched caterpillars of $H$. erato phyllis routinely cannibalize neighboring eggs. While the eggs of both sibling and unrelated individuals can be preyed upon, sibling eggs are cannibalized significantly less frequently than unrelated eggs (De Nardin and Araújo, 2011). This is an example of kin recognition, which can be strictly defined as the ability to identify a relationship as identical by descent (Hamilton, 1964a,b; Breed, 2014). In a recent study published by our group, we found a genetic component to the non-cannibalistic behavior, a characteristic associated with the recognition of relatedness (De Nardin et al., 2017). We observed that the frequency of non-cannibalism increases in offspring of inbred crosses. Cannibalistic behavior is thought to be influenced by several genes, or QTLs, and the assumption is that the manifestation of a non-cannibalistic phenotype depends on a threshold for their joint expression. Here, we present a preliminary study, in which we explored molecular marker genotyping strategies in order to search for associations between egg-cannibalism as a kin recognition behavioral phenotype, and AFLP and SSR alleles and genotypes.

\section{Material and Methods}

\section{Butterflies and experimental design}

Heliconius erato phyllis females were captured from 2011 to 2014 in nine wild populations. These were distant from each other by at least $2 \mathrm{~km}$ until $160 \mathrm{~km}$, and all of them were located in the state of Rio Grande do Sul, Brazil. Females were maintained in open air insectaries measuring approximately $3 \times 2 \times 2 \mathrm{~m}$ (length $\mathrm{x}$ width $\mathrm{x}$ height) at the Department of Genetics, Universidade Federal do Rio Grande do Sul, Porto Alegre, RS, Brazil. Females of this species are monandric, so that eggs laid by a single female are certain to be full siblings. The experimental design followed De Nardin and Araújo (2011). The females had already mated in the wild. Eggs were collected daily with the aid of brushes and placed at the vertices of an equilateral triangle made of green paper cardboard with a side length of
$0.5 \mathrm{~cm}$. The triangles were kept at room temperature in Petri dishes ( $8 \mathrm{~cm}$ in diameter and $1.5 \mathrm{~cm}$ in height) and covered with a lightly moistened paper towel to prevent dehydration of the eggs. Upon hatching of the first caterpillar, the presence/absence of cannibalism toward the remaining eggs was observed over a 45 minute period. We employed two experimental designs:

(1) Tests with sibling eggs only. In this case, whenever cannibalism occurred, the caterpillar had either not recognized the sibling egg, or was hungry enough to cannibalize it anyway (evidence from previous experiments indicated that there was kin recognition). This behavioral phenotype was represented as $\mathrm{C}$. The absence of cannibalism likely meant that the caterpillar had recognized the egg as being that of a sibling; this phenotype was represented as $\mathrm{NC}$.

(2) Tests with two sibling eggs and a non-related egg. These tests were valid for our purposes if the first egg to hatch was one of the siblings. In this case, the following phenotypes were possible: cannibalism of a sibling egg (no sibling recognition, represented as CNR), cannibalism of a non-related egg (sibling recognition; CR), cannibalism of both eggs ("super cannibal"; SC), and finally, no cannibalism at all ("super non-cannibal"; SNC).

Immatures hatched as part of these experiments were reared in the laboratory at a controlled temperature $\left(25^{\circ} \mathrm{C}\right)$ and were fed daily with Passiflora suberosa until they reached the adult stage. Adults hatched in experiment 1 were subjected to either outbred or inbred crosses, as described in the following. Outbred crosses: FNC x MC (four repeats), FC x M NC (four repeats), FC x MC (two repeats), and FNC x MNC (two repeats). Inbred crosses: FC x M C (two repeats), FNC x MNC (three repeats) and FNC x MC (one repeat). Adults hatched in experiment 2 were subjected to outbred crosses, as follows: FCR x MCNR (one repeat), FCNR x MNCS (two repeats), and FCS x MCS (one repeat). Finally, the egg-cannibalism experiments were repeated with the eggs from these crosses. Eggs of caterpillars hatched as part of experiment 1 were subjected to experimental design 1, eggs of caterpillars hatched as part of experiment 2 were subjected to experimental design 2 .

\section{Molecular markers}

Total DNA for genotyping was extracted from adult individuals following the protocol described by Mega and Revers (2011) and diluted to a concentration of $50 \mathrm{ng} / \mu \mathrm{L}$ for use in AFLP and SSR assays.

AFLPs markers were obtained from the AFLP Plant Mapping Protocol (Applied Biosystems, P/N 4303146F). Adapter ligation and pre-selective amplification were performed using the AFLP ${ }^{\circledR}$ Ligation and Preselective Amplification Module for Small Genomes (Applied Biosystems, Foster City, CA, USA) and EcoRI and MseI restriction enzymes. Selective amplification was performed using the AFLP ${ }^{\circledR}$ Selective Amplification Primers (Applied Bio- 
systems), using 12 primer pair combinations: EcoRI-TAJOE (green fluorescence)/MseI-CAA, EcoRI-TAJOE/MseI-CAC, EcoRI-TA-JOE/MseI-CTG, EcoRI-TA$\mathrm{JOE} / M s e \mathrm{I}-\mathrm{CTT}, \quad E c o$ RI-TG-FAM (blue fluorescence)/MseI-CAA, EcoRI-TG-FAM/MSeI-CAC, EcoRITG-FAM/MseI-CTG, EcoRI-TG-FAM/MseI-CTT, EcoRI-TT-NED (yellow fluorescence)/MseI-CAA, EcoRI-TT-NED/MSeI-CAC, EcoRI-TT-NED/MseI-CTG, EcoRI-TT-NED/MseI-CTT. PCR amplifications were done in a total volume of $10 \mu \mathrm{L}$ containing $1.5 \mu \mathrm{L}$ of DNA from the pre-selective amplification step, $0.5 \mu \mathrm{L}$ of $M s e \mathrm{I} 5$ un primer, $0.5 \mu \mathrm{L}$ EcoRI 1 un primer, $1 \mu \mathrm{L}$ of $10 \mathrm{x}$ buffer, $0.3 \mu \mathrm{L}$ of $\mathrm{MgCl}_{2} 50 \mathrm{mM}, 0.1 \mu \mathrm{L}$ of dNTP $10 \mathrm{mM}, 0.05$ of $\mu \mathrm{L}$ Platinum Taq DNA polymerase (Invitrogen/Thermo Fisher Scientific, Inc.) $(5 \mathrm{u} / \mu \mathrm{L})$, and $6.05 \mu \mathrm{L}$ of water. $\mathrm{Cy}-$ cling conditions followed the instructions in the AFLP Plant Mapping Protocol.

The samples obtained with the MseI-CAA and MseICAC extensions were analyzed on an ABI PRISM 310 Genetic Analyzer (Applied Biosystems) at the Laboratory of Plant Molecular Genetics (Embrapa Uva e Vinho, Bento Gonçalves, RS, Brazil) using $12 \mu \mathrm{L}$ of formamide, $0.3 \mu \mathrm{L}$ of GeneScan Rox-500 and $1 \mu \mathrm{L}$ of undiluted PCR product. Samples with MseI-CTG and MseI-CTT extensions were analyzed on an ABI3730 Genetic Analyzer at the Human Genome and Stem Cell Research Center (Universidade de São Paulo, São Paulo, SP, Brazil) using $8.925 \mu \mathrm{L}$ of formamide, $0.3 \mu \mathrm{L}$ of GeneScan Rox-500 and $1 \mu \mathrm{L}$ of undiluted PCR product. A signal-detection threshold of 100 RFU was applied, and markers between 50 and 500 bp were selected for analysis. GeneMapper v. 5 was used to generate a presence/absence (1/0) matrix for each of the markers. Table 1 shows the total number of markers obtained from each combination of primers.

We analyzed three microsatellite loci: Hel-01, Hel-08 and Hel-13 (Flanagan et al., 2002), all labeled with FAM (blue fluorescence). Microsatellites, or SSR markers, are co-dominant and highly polymorphic (Hall et al., 2010), though more laborious to obtain than AFLPs (Erickson et al., 2004). Details of the primers used are shown in Table 2. PCR amplification was performed in a total volume of $10 \mu \mathrm{L}$ containing $1 \mu \mathrm{L}$ of DNA $(50 \mathrm{ng} / \mu \mathrm{L}), 0.3 \mu \mathrm{L}$ of
Table 1 - Polymorphic markers obtained with the EcoRI and MseI primers used in this study.

\begin{tabular}{lccccc}
\hline \multirow{2}{*}{ Extension EcoRI } & \multicolumn{4}{c}{ Extension Mse I } & \multirow{2}{*}{ Total } \\
\cline { 2 - 5 } & CAA & CAC & CTG & CTT & \\
\hline TA & 372 & 346 & 440 & 319 & 1477 \\
TT & 86 & 55 & 193 & 138 & 472 \\
TG & 242 & 65 & 406 & 352 & 1065 \\
Total & 700 & 466 & 1039 & 809 & 3014 \\
\hline
\end{tabular}

$\mathrm{MgCl}_{2} 50 \mathrm{mM}, 0.1 \mu \mathrm{L}$ of dNTP $10 \mathrm{mM}, 1 \mu \mathrm{L}$ of buffer $10 \mathrm{x}$, $0.1 \mu \mathrm{L}$ of primer forward+reverse $(10 \mu \mathrm{M}), 0.05 \mu \mathrm{L}$ of Platinum Taq DNA polymerase $(5 \mathrm{u} / \mu \mathrm{L})$ and $7.45 \mu \mathrm{L}$ of water. PCR products were analyzed on an ABI3730 Genetic Analyzer at Macrogen Inc (Seoul, South Korea). Results were analyzed using GeneMapper 5. A presence/absence matrix, similar to that obtained for the AFLPs, was created for each allele. In addition, since microsatellites are co-dominant, a genotype table was also generated for each locus.

\section{Statistical analysis}

To identify AFLP and SSR markers associated with the phenotypes under consideration, we performed a chisquare $\left(\chi^{2}\right)$ single marker association test on the presence/absence matrix for each AFLP and SSR marker, using Microsoft Excel 2007 and PASW Statistics for Windows, version 18.0 (SPSS Inc., Chicago, USA). Yates' correction was applied to the chi-square tests on the $2 \times 2$ contingency tables for AFLP markers and the cannibalism/non-cannibalism phenotype (experimental design 1). Markers found to be statistically associated with the phenotypes were subjected to a logistic regression analysis with three "null" markers as covariates. Null markers are not in linkage disequilibrium with the gene being tested for association (Setakis et al., 2006) and are, thus, assumed to have a neutral effect on the phenotype of interest (Abdurakhmonov and Abdukarimov, 2008). They were included in the regression analysis to reduce the effect of population structure (Balding, 2006). Logistic regression was also performed using PASW Statistics for Windows, version 18.0.

In addition, a genotype association test was performed for all microsatellite markers, again through the ap-

Table 2 - Microsatellite primers and PCR amplification conditions used in this work.

\begin{tabular}{|c|c|c|c|c|c|c|}
\hline Locus & Primer name & Chromosome & Primer sequence & Repetition & Allele number & $\begin{array}{c}\text { Annealing } \\
\text { temperature }\left({ }^{\circ} \mathrm{C}\right)\end{array}$ \\
\hline \multirow[t]{2}{*}{ Hel-01 } & B6R & Z & 5'-TCGTAGATATCCATTACTCTGGTCTG-3' & $(\mathrm{GA})_{21}$ & 18 & 54 \\
\hline & $\mathrm{B} 6 \mathrm{~F}$ & & 5'-AGGGCGTCGTTAGTTTGTGT-3' & & & \\
\hline \multirow[t]{2}{*}{ Hel-08 } & $\mathrm{A} 2 \mathrm{~F}$ & 12 & 5'-ACATCTCAGAACTGGTCGGC-3' & $(\mathrm{CA})_{14}$ & 8 & 55 \\
\hline & $\mathrm{A} 2 \mathrm{R}$ & & 5'-CTCGATCAGCCGGTGATTAT-3' & & & \\
\hline \multirow[t]{2}{*}{ Hel-13 } & CA13F & 2 & 5'-ATTTCATAGTAACGCCCTCC-3' & $(\mathrm{CA})_{13}$ & 8 & 52 \\
\hline & CA13R & & 5'-TGACTTATCGCTAAGGTCAA-3' & & & \\
\hline
\end{tabular}


plication of a $\chi^{2}$ test. Finally, a further $\chi^{2}$ test was conducted on the full spectrum of alleles at each microsatellite locus. This analysis is different from the analysis of individual alleles described above, as it considers all alleles at a locus together.

\section{Results}

General information about butterfly families genotyped as part of this work is shown in Tables 3 and 4 . The Yates-corrected $\chi^{2}$ test identified associations between 72 of 3014 AFLP markers and the cannibalism/non-canni- balism phenotype from experimental design 1 (see Table $\mathrm{S} 1$ for details on these markers). For 20 markers, the association remained statistically significant after logistic regression (Table 5).

In the single-marker test of the phenotypes of experimental design 2 (cannibal that recognizes siblings, CR; cannibal that does not recognize siblings, CNR; "super cannibal", SC; and "super non-cannibal", SNC), a statistically significant association was found for 73 AFLPs (see Table $\mathrm{S} 2$ for details on these markers). For 11 markers, the association remained statistically significant after logistic regression (Table 6).

Table 3 - Genotyped families, for experiment 1 (two behavioral phenotypes: cannibals (C) and non-cannibals (NC)). The table shows the identification of each family, the behavior displayed by parents, the inbreeding coefficient of the offspring (F), the absolute frequency of the behavior observed by the offspring, the total number of offspring that was generated, the number of genotyped offsping, and the sex if genotyped parents.

\begin{tabular}{|c|c|c|c|c|c|c|c|c|}
\hline \multirow[t]{2}{*}{ Family } & \multicolumn{2}{|c|}{ Parent's Behavior } & \multirow[t]{2}{*}{$\mathrm{F}$} & \multicolumn{2}{|c|}{ Offspring's Behavior } & \multirow{2}{*}{$\begin{array}{l}\text { Total number of } \\
\text { offspring }\end{array}$} & \multirow{2}{*}{$\begin{array}{l}\text { Number of genotyped } \\
\text { offspring }\end{array}$} & \multirow{2}{*}{$\begin{array}{l}\text { Sex of genotyped } \\
\text { parents }\end{array}$} \\
\hline & Mother & Father & & $\mathrm{C}$ & $\mathrm{NC}$ & & & \\
\hline 1 & $\mathrm{C}$ & $\mathrm{C}$ & 0.25 & 2 & 13 & 15 & 2 & M \\
\hline 2 & $\mathrm{NC}$ & $\mathrm{NC}$ & 0.25 & 6 & 2 & 8 & 2 & M \\
\hline 3 & $\mathrm{NC}$ & $\mathrm{C}$ & 0 & 17 & 12 & 29 & 7 & M \\
\hline 4 & $\mathrm{C}$ & $\mathrm{NC}^{*}$ & 0 & 5 & 4 & 9 & 6 & $\mathrm{~F}, \mathrm{M}^{*}$ \\
\hline 5 & $\mathrm{NC}$ & $\mathrm{C}$ & 0 & 16 & 3 & 19 & 8 & $\mathrm{~F}, \mathrm{M}$ \\
\hline 6 & $\mathrm{C}$ & $\mathrm{C}$ & 0 & 6 & 4 & 10 & 8 & $\mathrm{~F}$ \\
\hline 7 & $\mathrm{C}$ & $\mathrm{NC}^{*}$ & 0 & 12 & 2 & 14 & 10 & $\mathrm{~F}, \mathrm{M}^{*}$ \\
\hline 8 & $\mathrm{C}$ & $\mathrm{C}$ & 0.25 & 2 & 12 & 14 & 12 & M \\
\hline 9 & $\mathrm{NC}$ & $\mathrm{C}$ & 0.25 & 6 & 14 & 20 & 10 & M \\
\hline 10 & $\mathrm{C}$ & $\mathrm{NC}$ & 0 & 20 & 18 & 38 & 9 & $\mathrm{~F}, \mathrm{M}$ \\
\hline 11 & $\mathrm{NC}$ & $\mathrm{C}$ & 0 & 13 & 21 & 34 & 10 & $\mathrm{~F}, \mathrm{M}$ \\
\hline 12 & $\mathrm{C}$ & $\mathrm{C}$ & 0 & 4 & 2 & 6 & 5 & $\mathrm{M}$ \\
\hline 13 & $\mathrm{NC}$ & $\mathrm{NC}$ & 0.25 & 4 & 14 & 18 & 8 & $\mathrm{~F}$ \\
\hline 14 & $\mathrm{NC}$ & $\mathrm{C}$ & 0 & 7 & 6 & 13 & 7 & - \\
\hline 15 & $\mathrm{NC}$ & $\mathrm{NC}$ & 0.25 & 4 & 10 & 14 & 4 & F \\
\hline 16 & $\mathrm{C}$ & $\mathrm{NC}$ & 0 & 17 & 14 & 31 & 6 & - \\
\hline 17 & $\mathrm{NC}$ & $\mathrm{NC}$ & 0 & 13 & 9 & 22 & 6 & - \\
\hline TOTAL & & & & 154 & 160 & 314 & 120 & 18 \\
\hline
\end{tabular}

*Single individual. $\mathrm{M}=$ Male; $\mathrm{F}=$ Female.

Table 4 - Genotyped families, from experimental design 2 (separation of four behavioral phenotypes: cannibal recognizing siblings (CR), cannibal that does not recognize siblings (CNR), super cannibal (SC) and super non-cannibal (SNC)). Abbreviations are the same as in Table 3.

\begin{tabular}{|c|c|c|c|c|c|c|c|c|c|c|}
\hline \multirow[t]{2}{*}{ Family } & \multicolumn{2}{|c|}{ Parent's behavior } & \multirow[t]{2}{*}{$\mathrm{F}$} & \multicolumn{4}{|c|}{ Offsprig's behavior } & \multirow{2}{*}{$\begin{array}{l}\text { Total number of } \\
\text { offspring }\end{array}$} & \multirow{2}{*}{$\begin{array}{l}\text { Number of genotyped } \\
\text { offspring }\end{array}$} & \multirow{2}{*}{$\begin{array}{l}\text { Sex of genotyped } \\
\text { parents }\end{array}$} \\
\hline & Mother & Father & & $\mathrm{CR}$ & CNR & $\mathrm{SC}$ & $\mathrm{SNC}$ & & & \\
\hline 1 & $\mathrm{CR}$ & CNR & 0 & 7 & 6 & 7 & 3 & 23 & 16 & M \\
\hline 2 & CNR & $\mathrm{SNC}^{*}$ & 0 & 8 & 5 & 1 & 5 & 19 & 9 & $\mathrm{~F}, \mathrm{M}^{*}$ \\
\hline 3 & CNR & $\mathrm{SNC}^{*}$ & 0 & 15 & 4 & 3 & 15 & 37 & 24 & $\mathrm{~F}, \mathrm{M}^{*}$ \\
\hline 4 & $\mathrm{SC}$ & $\mathrm{SC}$ & 0 & 2 & 4 & 2 & 3 & 11 & 7 & $\mathrm{~F}, \mathrm{M}$ \\
\hline Total & & & & 32 & 19 & 13 & 26 & 90 & 56 & 6 \\
\hline
\end{tabular}

*Single individual. $\mathrm{M}=$ Male; $\mathrm{F}=$ Female. 
Table 5 - AFLP markers that showed significant $P$ values in $\chi^{2}$ tests and logistic regression between the presence (1) and absence of allele (0) and the cannibal and non-cannibal phenotypes. The extensions used (to EcoRI and $M s e$ ) to obtain the fragment, and also the fragment size (bp) are also indicated. In columns "Non-cannibal" and "Cannibal" are shown the absolute frequencies observed for the presence and absence of the band for each behavioral phenotype. The Mendelian segregation of markers was tested when possible, and are represented in bold in column Marker.

\begin{tabular}{|c|c|c|c|c|c|c|c|c|c|c|}
\hline \multirow[t]{2}{*}{ Marker } & \multicolumn{2}{|c|}{ Extensions } & \multirow[t]{2}{*}{$\mathrm{bp}$} & \multicolumn{2}{|c|}{ Non-cannibal } & \multicolumn{2}{|c|}{ Cannibal } & \multirow[t]{2}{*}{$\chi_{\text {Yates }}^{2}$} & \multirow[t]{2}{*}{$P_{x^{2}}$} & \multirow[t]{2}{*}{$P_{\text {Logistic Regression }}$} \\
\hline & EcoRI- & MseI- & & 0 & 1 & 0 & 1 & & & \\
\hline 49 & TG & CTG & 90 & 50 & 15 & 35 & 27 & 5.119 & $0.024^{\mathrm{a}}$ & 0.048 \\
\hline 55 & TG & CTG & 96 & 57 & 8 & 62 & 0 & 6.192 & $0.013^{\mathrm{b}}$ & 0.008 \\
\hline 97 & TG & CTG & 130 & 58 & 7 & 62 & 0 & 5.150 & $0.023^{\mathrm{b}}$ & 0.027 \\
\hline 206 & TG & CTG & 219 & 31 & 34 & 49 & 13 & 12.059 & $0.001^{\mathrm{b}}$ & 0.003 \\
\hline 275 & TG & CTG & 280 & 65 & 0 & 56 & 6 & 4.627 & $0.031^{\mathrm{a}}$ & 0.034 \\
\hline 276 & TG & CTG & 281 & 62 & 3 & 49 & 13 & 6.292 & $0.012^{\mathrm{a}}$ & 0.040 \\
\hline 447 & TA & CTG & 83 & 56 & 9 & 42 & 21 & 5.728 & $0.017^{\mathrm{a}}$ & 0.026 \\
\hline 531 & TA & CTG & 156 & 57 & 8 & 63 & 0 & 6.304 & $0.012^{\mathrm{b}}$ & 0.016 \\
\hline 983 & $\mathrm{TT}$ & CTG & 205 & 47 & 10 & 51 & 1 & 5.693 & $0.017^{\mathrm{b}}$ & 0.050 \\
\hline 1092 & TG & CTT & 100 & 54 & 11 & 62 & 1 & 7.143 & $0.008^{\mathrm{b}}$ & 0.040 \\
\hline 1098 & TG & CTT & 103 & 27 & 38 & 42 & 21 & 7.150 & $0.007^{\mathrm{b}}$ & 0.029 \\
\hline 1120 & TG & CTT & 124 & 15 & 50 & 32 & 31 & 9.418 & $0.002^{\mathrm{b}}$ & 0.026 \\
\hline 1127 & TG & CTT & 130 & 59 & 6 & 43 & 20 & 8.677 & $0.003^{\mathrm{a}}$ & 0.008 \\
\hline 1295 & TG & CTT & 267 & 56 & 9 & 36 & 27 & 11.923 & $0.001^{\mathrm{a}}$ & 0.000 \\
\hline 1306 & TG & CTT & 277 & 64 & 1 & 53 & 10 & 6.643 & $0.010^{\mathrm{a}}$ & 0.020 \\
\hline 1358 & TG & CTT & 344 & 65 & 0 & 56 & 7 & 5.642 & $0.018^{\mathrm{a}}$ & 0.017 \\
\hline 1484 & $\mathrm{TA}$ & CTT & 127 & 61 & 4 & 49 & 14 & 5.570 & $0.018^{\mathrm{a}}$ & 0.031 \\
\hline 1563 & TA & CTT & 205 & 64 & 1 & 49 & 14 & 11.306 & $0.001^{\mathrm{a}}$ & 0.000 \\
\hline 2018 & $\mathrm{TA}$ & CAA & 196 & 68 & 0 & 64 & 6 & 4.207 & $0.040^{\mathrm{a}}$ & 0.033 \\
\hline 2314 & TG & CAA & 232 & 65 & 3 & 57 & 13 & 5.436 & $0.020^{\mathrm{a}}$ & 0.032 \\
\hline
\end{tabular}

${ }^{\mathrm{a}}$ presence of marker most common in cannibals.

${ }^{\mathrm{b}}$ presence of marker most common in non-cannibals.

The results of association analyses between the microsatellite markers (Hel-01, Hel-08 and Hel-13) and the phenotypes of experimental design $1(\mathrm{C}$ and $\mathrm{NC})$ are shown in Table 7. For Hel-13, a significant association was found in the test considering all alleles together $(P=0.004 ; 7 \mathrm{df})$. Alleles 229 bp, 241 bp and 255 bp were more common in non-cannibals, and alleles $233 \mathrm{bp}, 235 \mathrm{bp}$ and $237 \mathrm{bp}$ were more common in cannibals. The $P$ value for Hel-08 was near significance $(P=0.051 ; 7 \mathrm{df})$. Allele $283 \mathrm{bp}$ was more common in non-cannibals, and allele 296 bp was more common in cannibals. Genotype association analysis identified an association with the Hel-08 locus $(P=0.017$; $18 \mathrm{df})$. Genotypes 273pb / 273pb and 273pb / 279pb were more common in cannibals, and genotypes $281 \mathrm{pb} / 283 \mathrm{pb}$ and $273 \mathrm{pb} / 283 \mathrm{pb}$ were more common in non-cannibals.

The analysis of the microsatellite markers and the phenotypes of experimental design 2 (CR, CNR, SC, and $\mathrm{SNC}$ ) identified a single significant association based on the presence or absence of each individual allele, for the 403 bp allele at the Hel-01 locus $\left(P=0.027\right.$ in the $\chi^{2}$ test $)$. However, statistical significance was not maintained after logistic regression $(P=0.106)$. No associations were found for these phenotypes in the joint analysis of all alleles and in the genotypic analyses.

After logistic regression, none of the markers showed a significant association with the phenotypes of both experimental designs. However, based on the $\chi^{2}$ test, five markers (AFLPs 78, 146, 315, 1484 and 1563) were found to be associated with the phenotypes tested in both experimental designs. Details of these markers can be found in Tables S1 and S2.

\section{Discussion}

Our preliminary study identified a number of associations between molecular markers and phenotypes for both experimental designs employed here. For experimental design 1, which distinguished between cannibal and noncannibal phenotypes, associations with the non-cannibal phenotype were found for AFLPs 206, 1098, and 1120, and for the SSRs Hel-08 and Hel-13, as well as for the cannibal phenotype $(49,447,1127,1295)$. For experimental design 2 , which distinguished between four behavioral phenotypes (cannibal that recognizes siblings, cannibal that does not recognize siblings, super cannibal and super non-cannibal), 
Table 6 - AFLP markers that showed significant $P$ values in $\chi^{2}$ tests and logistic regression, for association between the presence (1) and absence (0) of allele and phenotypes "cannibals which recognize siblings" (CR), "cannibals which does not recognize siblings" (CNR), "super cannibal" (SC) and "super non-cannibal" (SNC). The extensions used are indicated (EcoRI and MseI) to obtain fragment, and also the fragment size (bp). In columns "CR", "CNR", "SC" and "SNC" the absolute frequencies are shown for the presence/absence of the band for each behavioral phenotype. The Mendelian segregation of markers was tested when possible, and is represented in bold in column Marker.

\begin{tabular}{|c|c|c|c|c|c|c|c|c|c|c|c|c|c|c|}
\hline \multirow[t]{2}{*}{ Marker } & \multicolumn{2}{|c|}{ Extensions } & \multirow[t]{2}{*}{$\mathrm{bp}$} & \multicolumn{2}{|c|}{$\mathrm{CR}$} & \multicolumn{2}{|c|}{ CNR } & \multicolumn{2}{|c|}{$\mathrm{SC}$} & \multicolumn{2}{|c|}{$\mathrm{SNC}$} & \multirow[t]{2}{*}{$\chi^{2}$} & \multirow{2}{*}{$P_{\chi^{2}}$} & \multirow[t]{2}{*}{$P_{\text {Logistic Regression }}$} \\
\hline & EcoRI- & MseI- & & 0 & 1 & 0 & 1 & 0 & 1 & 0 & 1 & & & \\
\hline 473 & TA & CTG & 104 & 14 & 5 & 10 & 5 & 8 & 3 & 3 & 14 & 14.5 & $0.002^{\mathrm{d}}$ & 0.025 \\
\hline 942 & $\mathrm{TT}$ & CTG & 148 & 17 & 2 & 7 & 8 & 6 & 5 & 16 & 1 & 14.0 & $0.003^{\mathrm{b}, \mathrm{c}}$ & 0.035 \\
\hline 1122 & TG & CTT & 125 & 19 & 0 & 9 & 6 & 10 & 1 & 17 & 0 & 17.0 & $0.001^{\mathrm{b}, \mathrm{c}}$ & 0.020 \\
\hline 1171 & TG & CTT & 165 & 14 & 0 & 13 & 2 & 11 & 0 & 7 & 10 & 14.1 & $0.003^{\mathrm{d}}$ & 0.024 \\
\hline 1185 & TG & CTT & 176 & 19 & 5 & 13 & 2 & 11 & 0 & 8 & 9 & 21.1 & $<0.001^{\mathrm{d}}$ & 0.002 \\
\hline 1466 & TA & CTT & 114 & 5 & 14 & 5 & 10 & 10 & 1 & 8 & 9 & 13.0 & $0.005^{\mathrm{a}, \mathrm{b}, \mathrm{d}}$ & 0.040 \\
\hline 2133 & TA & CAA & 82 & 11 & 8 & 9 & 6 & 11 & 0 & 17 & 0 & 15.0 & $0.002^{\mathrm{a}, \mathrm{b}}$ & 0.009 \\
\hline 2151 & TA & CAA & 96 & 2 & 17 & 10 & 5 & 3 & 8 & 2 & 15 & 16.4 & $0.001^{\mathrm{a}, \mathrm{d}}$ & 0.021 \\
\hline 2168 & TA & CAA & 108 & 19 & 0 & 11 & 4 & 8 & 3 & 17 & 0 & 10.9 & $0.012^{\mathrm{b}, \mathrm{c}}$ & 0.026 \\
\hline 2215 & TA & CAA & 146 & 11 & 8 & 8 & 7 & 7 & 4 & 17 & 0 & 10.7 & $0.014^{\mathrm{a}, \mathrm{b}, \mathrm{c}}$ & 0.040 \\
\hline 2493 & TT & CAA & 78 & 13 & 6 & 8 & 7 & 7 & 4 & 2 & 15 & 13.3 & $0.004^{\mathrm{d}}$ & 0.031 \\
\hline
\end{tabular}

${ }^{\text {a }}$ presence of marker most common in CR

${ }^{\mathrm{b}}$ presence of marker most common in CNR

${ }^{\mathrm{c}}$ presence of marker most common in SC.

${ }^{\mathrm{d}}$ presence of marker most common in SNC.

Table 7 - Microsatellite markers that resulted in a statistically significant association between the presence/absence of the mark and behavioral phenotype. The name of the locus, allele size (bp), the absolute frequencies of presence/absence of alleles for each behavioral phenotype, the value of $\chi^{2}$ with Yates correction, the corresponding $P$ value, and the value of $P$ resulting logistic regression are all shown.

\begin{tabular}{|c|c|c|c|c|c|c|c|c|}
\hline \multirow[t]{2}{*}{ Locus } & \multirow[t]{2}{*}{ bp } & \multicolumn{2}{|c|}{ Non-cannibal } & \multicolumn{2}{|c|}{ Cannibal } & \multirow{2}{*}{$\chi_{\text {Yates }}^{2}$} & \multirow{2}{*}{$P_{\chi^{2}}$} & \multirow{2}{*}{$P_{\text {Logistic regression }}$} \\
\hline & & 0 & 1 & 0 & 1 & & & \\
\hline Hel-08 & 283 & 31 & 34 & 48 & 19 & 6.91 & 0.009 & 0.034 \\
\hline Hel-13 & 229 & 45 & 21 & 27 & 38 & 8.34 & 0.002 & 0.014 \\
\hline Hel-13 & 233 & 50 & 15 & 37 & 29 & 4.49 & 0.019 & 0.038 \\
\hline
\end{tabular}

a number of observations were made. Certain markers, such as AFLP 473, were more common in super noncannibals (SNC); others, including AFLP 2151, were more common in cannibals that recognize siblings and in super non-cannibals, both being phenotypes related to kin recognition. On the other hand, there were markers, such as AFLPs 1122 and 2168, that were absent in these phenotypes.

The striking frequency of "kin recognition" behavioral phenotypes observed in the offspring of family 3 , which was obtained as part of experiment 2 (Table 4), is particularly noteworthy. The family produced a total of 37 offspring. Of these, $40.5 \%$ cannibalized unrelated eggs only, $40.5 \%$ did not cannibalize any eggs, $11 \%$ were cannibals that did not recognize siblings, and $8 \%$ were supercannibals. These figures mean that $81 \%$ of the offspring from this family showed kin recognition behavior. This high prevalence of kin recognition within a family is in accordance with our previous report, in which we presented evidence for the heritability of kin recognition (De Nardin et al., 2017). Another possibility, which cannot be entirely discarded, is that this unusual spectrum of phenotypes is due to the effect of genes associated with cannibalism itself, rather than kin recognition.

Hamilton (1964a,b) showed how altruism could evolve if 'genes for altruism' had the effect of increasing the fitness of relatives, even in the case of costs to the altruist. Thompson et al. (2013) formulated a set of testable hypotheses describing the evolution, expression and features expected for such genes for altruism. Genes underlying altruism: (i) should satisfy Hamilton's Rule $r b>c$, where $r$ is the genetic relationship between the altruist and recipient, $b$ is the benefit for the recipient, and $c$ the cost to the altruist; (ii) should be environmentally sensitive; (iii) should increase in number and complexity with increasing socialbehavioral organization; (iv) should coevolve with or depend on the previous evolution of genes for kin recognition; (v) may reside in regions of low recombination, to show 
co-expression and modular genetic architecture; (vi) should be at least partially additive, and (vi) should exhibit strong pleiotropy. From our own experience in the field and laboratory (De Nardin J, 2012, MSc thesis, Universidade Federal do Rio Grande do Sul, Porto Alegre, RS, Brazil; De Nardin and Araújo, submitted), the avoidance of sibling egg-cannibalism by caterpillars of $H$. erato phyllis is compatible with Hamilton's rule. We furthermore observed, both in the field and experimentally, an environmental dependency of cannibalistic behavior (Huff, De Nardin and Araújo, unpublished results). If there are genes for cannibalism, condition (ii) above could be fulfilled.

Association analyses have been used as a tool for the identification of population-wide polymorphisms associated with particular phenotypes (Parker TB, 2007, Doctoral thesis. Oregon State University, USA). These associations arise due to the joint transmission of phenotypes and genotypes over many generations. Association analysis does not model these transmissions directly, although linkage analysis does. Relationships between individuals are central to linkage analysis; in association analysis, these relationships are usually distant or unknown, and where present, close relationships are a complicating factor (Astle and Balding, 2009). Population structure, or stratification, can lead to spurious associations (association without linkage) between a candidate marker and the phenotype. Several methods have been developed to reduce such spurious associations (Pritchard et al., 2000; Wang et al., 2005; Yu et al., 2005; Zhu et al., 2008; Zhang et al., 2009; Thornton et al., 2014). Here, this was achieved by using null markers as covariates in the logistic regression analysis (Wang et al., 2005; Setakis et al., 2006).

Because our analyses included families, genetic structure was an issue. However, our experiments could not reasonably have been performed in a random population sample. The kin recognition phenotypes studied here (cannibal/non-cannibal) could not have been determined other than through a laboratory-based behavioral test. Therefore, we have chosen to perform various kinds of crosses between parents with different behavioral phenotypes, and from different populations. We have included inbred crosses in our approach, which we know occur in nature (Di Mare and Araújo, 1986). Moreover, all behavioral phenotypes, both from experiment 1 and experiment 2 , were present in the offspring of all families. That is, the subgroups are phenotypically similar in terms of the characteristics here analyzed, despite possible genetic differentiation. Furthermore, we corrected spurious associations by logistic regression using neutral, unlinked markers, a common practice in genetic association studies. Of the 72 associations initially identified by the $\chi^{2}$ test in experiment 1 , only 20 remained statistically significant after logistic regression with null markers. Of the 73 associations initially found in experiment 2, 11 remained significant. Setakis et al. (2006) conducted a simulation study to compare the merits of different methods that use null (unlinked) markers, to protect against critical substructures in genetic association studies. One of the most important findings from their study was that simple statistical procedures, based on logistic regression, performed well in all scenarios considered. Methods based on logistic regression do not require an estimate of the number of underlying subpopulations; in fact, they dispense entirely with the notion of subpopulation. One possible explanation for their effectiveness is that each null marker included in the regression absorbs part of the effect of population stratification, but because this effect is shared across many markers, none of the markers is individually significant. Wang et al. (2005) showed that it is possible to control for population structure within a logistic regression model by including the genotype of a single marker that is informative about ancestry among the covariates.

To detect a QTL using single-marker tests is a simple procedure that can be performed with any statistical analysis software, and which has the potential to identify a significant number of markers (Doerge, 2002). However, some issues need to be considered in the statistical analysis of the results. The first is sample size. A large sample size provides more opportunities for the observation of recombination events, allowing to estimate parameters with high accuracy and, therefore, results in a greater ability to detect QTLs (Doerge, 2002). The size of the sample used here was not large. This was in particular the case for experiment 2 , which may explain the lower number of associations found for that design. Another statistical problem associated with the use of small sample sizes is that they exaggerate the effect of a QTL on the phenotype in what is called the Beavis effect (Beavis, 1994; Erickson et al., 2004). Furthermore, single-marker analysis can only detect QTLs with a relatively large influence on the trait of interest. The current study design is likely to have a relatively modest power to identify QTLs. A further problem is introduced by the investigation of many markers using independent statistical tests, or multiple testing. This problem is related to the level of statistical significance which is established by the investigator and can lead to the detection of false positives. Typically, researchers tolerate the incorrect detection of a QTL in 5\% of the cases (Doerge, 2002). Associations that appear purely by chance are called "false positives", or type I errors. Type I errors can be minimized by establishing more stringent criteria for statistical significance, e.g. by applying a Bonferroni correction. However, as type I errors diminish, QTLs with small effect sizes are increasingly unlikely to be detected, thus increasing the probability of type II errors, or false negatives (Grisel, 2000).

Another limitation of single-marker strategies is that they fail to provide the frequency of recombination between the marker and the QTL, and thus the precise location of the QTL. This is because the effect of the QTL and its location are conflated and cannot be estimated sepa- 
rately (Doerge, 2002). The work presented here thus only represents a preliminary search for possible associations between genotype and phenotype. It does not aim at the exact mapping of QTLs, and to do so would require a single segregating population originating from a cross between individuals of contrasting phenotypes, and a fairly large number of offspring of at least 50 to 250 individuals would be needed to allow preliminary mapping (Collard et al., 2005), which was not possible here.

The ability to detect a QTL depends on the magnitude of its effect on the trait of interest, the size of the segregating population evaluated, the frequency of recombination between the marker and the QTL, as well as the heritability of the trait. The larger the effect size and the size of the population, the greater the heritability, and the smaller the distance between the QTL and the marker, the easier it becomes to detect the QTL (Ferreira and Gratapaglia, 1995). We have previously estimated the heritability of the noncannibalism phenotype to lie around 20\% (De Nardin et al., 2017); this relatively low value makes it difficult to detect the underlying QTLs.

QTLs affecting various quantitative characteristics, such as life span, starvation, reproductive success, number of sensory bristles, sex comb teeth and ovarioles, flight velocity and metabolic traits, courtship song, locomotor behavior and male mating and aggressive behavior have been mapped in Drosophila melanogaster (reviewed by Edwards and Mackay, 2009). Studies in honeybees (Apis mellifera) have identified QTLs that influence the expression of foraging and defensive behavior in colonies, specific individual behavior, the tendency of individuals perform guard and stinging behavior (reviewed by Arechavaleta-Velasco et al., 2003), as well as hygienic behavior (Lapidge et al., 2002). Caillaud and Via (2012) studied QTLs related to feeding behavior in the pea aphid Acyrthosiphon pisum. It should be emphasized that all of these studies deal with traits that can be measured on a continuous scale, while the phenotypes studied here, although they are also quantitative traits, are observed in a nonlinear way.

Linkage maps are available for Heliconius melpomene (Jiggins et al., 2005) and Heliconius erato (Tobler et al., 2005; Kapan et al., 2006). This has enabled the estimation of the sizes of these species' genomes. Both comprise 21 chromosomes, with a total of $1616 \mathrm{cM}$ or $292 \mathrm{Mb}$ for $H$. melpomene (Jiggins et al., 2005) and $2400 \mathrm{cM}$ or $395 \mathrm{Mb}$ for H. erato (Tobler et al., 2005). These maps were obtained by crossing individuals with contrasting phenotypes for a trait of interest (either within or even between species), and analyzing a large number of offspring (> 70 individuals) from each cross. We could not implement this approach for several reasons: (i) our phenotyping strategy depended on testing for cannibalism, which used three eggs at a time, meaning that not all offspring generated by a female butterfly reached adulthood; (ii) numerous tests had to be cancelled, either because cannibalism could not be de- tected unambiguously (due to bite marks on an egg not being clearly visible), because the stipulated test duration was exceeded, or because the eggs dried up during the test; (iii) many females died prematurely; (iv) many females laid only few eggs. It is important to note that all linkage maps are unique products of the population (derived from two specific parents) and the types of markers used (Collard et al., 2005). Therefore, even if we had performed many crosses between individuals of different populations, we would not be able to tell with certainty that all associations found here would be observed in other individuals from other populations.

We are aware of the potential problems inherent in our methodology, as well as of the limitations of this kind of preliminary study. Specifically, QTL analysis by a single marker does not allow to establish the location of a particular locus, thus preventing a linkage map. Nevertheless, our data indicate the likely presence of associations between AFLP and SSR markers and the behavioral phenotypes studied. We tested around 3,000 markers, an average of 7.6 markers per $\mathrm{Mb}$. The sampling of genetic variability however was sufficiently broad to ensure the reliability of the data and conclusions. Nevertheless, additional studies will be necessary to validate the associations found here, and to construct a linkage map of the markers used here, with the ultimate aim of identifying and mapping the main genetic factors involved in the control of the assessed phenotypes and measuring the magnitude of their effect. Likewise, a larger number of markers will have to be tested in regions harboring association signals to define more accurately the location of the loci of interest.

\section{Acknowledgments}

We would like to thank our colleagues Ana Carolina Aymone, Ana Carolina da Silva, André Klein, Bruna Missaggia, Etiele Silveira, Luciana da Silva, Marcelo Costa, Natasha Nonemacher Magni, Pietro Pollo, Rosana Huff, and Thiana Arisi for their help in caring for the butterflies and immature individuals. We also thank Estação Experimental Agronômica de Águas Belas (FEPAGRO, Rio Grande do Sul) and the Laboratory of Plant Molecular Genetics (Embrapa Uva e Vinho, Bento Gonçalves). Furthermore, we would like to thank the Conselho Nacional de Desenvolvimento Científico e Tecnológico (CNPq) for financial support and a $\mathrm{PhD}$ grant to Janaína De Nardin (141920/2012-2). Finally, we thank the Coordenação de Aperfeiçoamento de Pessoal de Nível Superior (CAPES), and the Postgraduate Program in Genetics and Molecular Biology (PPGBM) at UFRGS for providing financial aid and supporting this work.

\section{References}

Abdurakhmonov IY and Abdukarimov A (2008) Application of association mapping to understanding the genetic diversity 
of plant germplasm resources. Int $\mathrm{J}$ Plant Genomics 2008:574927.

Arechavaleta-Velasco ME, Hunt GJ and Emore C (2003) Quantitative trait loci that influence the expression of guarding and stinging behaviors of individual honey bees. Behav Genet 33:357-363.

Astle W and Balding DJ (2009) Population structure and cryptic relatedness in genetic association studies. Stat Sci 24:451-471.

Balding DJ (2006) A tutorial on statistical methods for population association studies. Nat Rev Genet 7:781-791.

Beavis WD (1994) The power and deceit of QTL experiments: Lessons from comparative QTL studies. In: Wilkinson DB (ed) Proceedings of the Forty-Ninth Annual Corn and Sorghum Industry Research Conference. American Seed Trade Association, Chicago, pp 250-266.

Breed MD (2014) Kin and nestmate recognition: The influence of W. D. Hamilton on 50 years of research. Anim Behav 92:271-279.

Brown Jr KS (1981) The biology of Heliconius and related genera. Annu Rev Entomol 26:427-456.

Bush WS and Moore JH (2012) Chapter 11: Genome-wide association studies. PLoS Comp Biol 8:e1002822.

Caillaud MC and Via S (2012) Quantitative genetics of feeding behavior in two ecological races of the pea aphid, Acyrthosiphon pisum. Heredity 108:211-218.

Collard BCY, Jahufer MZZ, Brouwer JB and Pang ECK (2005) An introduction to markers, quantitative trait loci (QTL) mapping and marker-assisted selection for crop improvement: The basic concepts. Euphytica 142:169-196.

De Nardin J and Araújo AM (2011) Kin recognition in immatures of Heliconius erato phyllis (Lepidoptera; Nymphalidae). J Ethol 29:499-503.

De Nardin J, Da Silva L and Araújo AM (2017) Kin recognition in a butterfly: inferences about its heritability. Ethol Ecol Evol 29:255-265.

Di Mare RA and Araújo AM (1986) A first survey of inbreeding effects in Heliconius erato phyllis (Lepidoptera; Nymphalidae). Rev Bras Genet 9:11-20.

Doerge RJ (2002) Mapping and analysis of quantitative trait loci in experimental populations. Nat Rev Genet 3:43-52.

Edwards AC and Mackay TFC (2009) Quantitative trait loci for aggressive behavior in Drosophila melanogaster. Genetics 182:889-897.

Erickson DL, Fenster CB, StenØien HK and Price D (2004) Quantitative trait locus analyses and the study of evolutionary process. Mol Ecol 13:2505-2522.

Falconer DS and Mackay TFC (1996) Introduction to Quantitative Genetics. 4th edition. Addison-Wesley Longman, Harlow, 480 p.

Ferreira ME and Gratapaglia D (1995) Introdução ao uso de marcadores RAPD e RFLP em análise genética. EMBRAPA-CENARGEN, Brasília, 220 p.

Flanagan NS, Blum MJ, Davison A, Alamo M, Albarrán R, Faulhaber K, Peterson E and McMillan WO (2002) Characterization of microsatellite loci in neotropical Heliconius butterflies. Mol Ecol Notes 2:398-401.

Ford EB (1964) Ecological Genetics. Methuen, London, 335 p.

Ford EB (1975) Ecological Genetics. 4th edition. Chapman and Hall, London, 442 p.
Grisel JE (2000) Quantitative trait locus analysis. Alcohol Res Health 24:169-174.

Hall D, Tegström C and Ingvarsson PK (2010) Using association mapping to dissect the genetic basis of complex traits in plants. Brief Funct Genomics 9:157-165.

Hamilton WD (1964a) Genetical evolution of social behavior. I. J Theor Biol 7:1-16.

Hamilton WD (1964b) Genetical evolution of social behavior. II. J Theor Biol 7:17-52.

Jiggins CD, Mavarez J, Beltrán M, McMillan WO, Johnston JS and Bermingham E (2005) A genetic linkage map of the mimetic butterfly Heliconius melpomene. Genetics 171:557-570.

Joron M, Frezal L, Jones RT, Chamberlain NL, Lee SF, Haag CR, Whibley A, Becuwe M, Baxter SW, Ferguson L, et al. (2011) Chromosomal rearrangements maintain a polymorphic supergene controlling butterfly mimicry. Nature 477:203-206.

Kapan DD, Flanagan NS, Tobler A, Papa R, Reed RD, Gonzalez JA, Restrepo MR, Martinez L, Maldonado K, Ritschoff C, et al. (2006) Localization of Müllerian mimicry genes on a dense linkage map of Heliconius erato. Genetics 173:735-757.

Kettlewell HBD (1955) Selection experiments on industrial melanism in the Lepidoptera. Heredity 9:323-342.

Lapidge KL, Oldroyd BP and Spivak M (2002) Seven suggestive quantitative trait loci influence hygienic behavior of honey bees. Naturwissenschaften 89:565-568.

Lynch M and Walsh B (1998) Genetics and Analysis of Quantitative Traits. Sinauer Associates, Sunderland, 980 p.

Mega NO and Revers LF (2011) Developing a rapid, efficient and low cost method for rapid DNA extraction from arthropods. Cienc Rural 41:1563-1570.

Merrill RM, Dasmahapatra KK, Davey JW, Dell'Aglio DD, Hanly JJ, Huber B, Jiggins CD, Joron M, Kozak KM, Llaurens V, et al. (2015) The diversification of Heliconius butterflies: What have we learned in 150 years? J Evol Biol 28:1417-1438.

Olson JM, Witte JS and Elston RC (1999) Tutorial in biostatistics genetic mapping of complex traits. Stat Med 18:2961-2981.

Pritchard JK, Stephens M and Donnelly P (2000) Inference of population structure using multilocus genotype data. Genetics 155:945-959.

Ramos RR and Freitas AVL (1999) Population biology and wing color variation in Heliconius erato phyllis (Nymphalidae). J Lepid Soc 53:11-21.

Roff DA, Tucker J, Stirling G and Fairbairn DJ (1999) The evolution of threshold traits: Effects of selection on fecundity and correlated response in wing dimorphism in the sand cricket. J Evol Biol 12:535-546.

Setakis E, Stirnadel H and Balding DJ (2006) Logistic regression protects against population structure in genetic association studies. Genome Res 16:290-296.

Thompson GJ, Hurd PL and Crespi BJ (2013) Genes underlying altruism. Biol Lett 9:20130395.

Thornton T, Conomos MP, Sverdlov S, Blue EM, Cheung CYK, Glazner CG, Lewis SM and Wijsman EM (2014) Estimating and adjusting for ancestry admixture in statistical methods for relatedness inference, heritability estimation, and association testing. BMC Proc 8(Suppl 1):S5. 
Tobler A, Kapan D, Flanagan NS, Gonzalez C, Peterson E, Jiggins CD, Johntson JS, Heckel DG and McMillan WO (2005) First-generation linkage map of the warningly colored butterfly Heliconius erato. Heredity 94:408-417.

Wang Y, Localio R and Rebbeck TR (2005) Bias correction with a single null marker for population stratification in candidate gene association studies. Hum Hered 59:165-175.

Wu R, Ma CX and Casella G (2002) Joint linkage and linkage disequilibrium mapping of quantitative trait loci in natural populations. Genetics 160:779-792.

Yu J, Pressoir G, Briggs WH, Bi IV, Yamasaki M, Doebley JF, McMullen MD, Gaut BS, Nielsen DM, Holland JB, et al. (2005) A unified mixed-model method for association mapping that accounts for multiple levels of relatedness. Nat Genet 38:203-208.

Zhang L, Li J, Pei YF, Liu Y and Deng HW (2009) Tests of association for quantitative traits in nuclear families using princi- pal components to correct for population stratification. Ann Hum Genet 73:601-613.

Zhu X, Li S, Cooper RS and Elston RC (2008) A unified association analysis approach for family and unrelated samples correcting for stratification. Am J Hum Genet 82:352-365.

\section{Supplementary material}

The following online material is available for this article: Table S1 - Significant AFLP markers: association of allele presence/absence with cannibalism phenotypes.

Table S2 - Significant AFLP markers: association of allele presence/absence with cannibalism/kin recognition phenotypes.

Associate Editor: Loreta B. Freitas

License information: This is an open-access article distributed under the terms of the Creative Commons Attribution License (type CC-BY), which permits unrestricted use, distribution and reproduction in any medium, provided the original article is properly cited. 